\title{
Validity of dietary patterns to assess nutrient intake adequacy
}

\author{
Blanca Román-Viñas ${ }^{1}$, Lourdes Ribas Barba ${ }^{1}$, Joy $\mathrm{Ngo}^{1}$, Miguel Ángel Martínez-González ${ }^{2}$, \\ Trudy M. A. Wijnhoven ${ }^{3}$ and Lluís Serra-Majem ${ }^{1,4} *$ \\ ${ }^{1}$ Community Nutrition Research Centre of the Nutrition Research Foundation, University of Barcelona Science Park, \\ Baldiri Reixac 4, 08028 Barcelona, Spain \\ ${ }^{2}$ Department of Epidemiology and Public Health, University of Navarra, Irunlarrea 1, 31080 Pamplona, Spain \\ ${ }^{3}$ Noncommunicable Disease and Environment World Health Organization Regional Office for Europe, Scherfigsvej 8, DK-2100 \\ Copenhagen $\emptyset$, Denmark \\ ${ }^{4}$ University of Las Palmas de Gran Canaria, PO Box 550, 35080 Las Palmas de Gran Canaria, Spain
}

(Received 5 March 2009 - Revised 6 May 2009 - Accepted 1 June 2009)

\begin{abstract}
The purpose of the present study was to conduct a systematic review of the literature on the value of the methods used to assess dietary patterns for measuring nutrient intake adequacy in the population. Systematic review on Pubmed database up to April 2008. The search included specific key words and MeSH terms. No language limit was set. Only studies that compared food patterns with nutrient intake adequacy or nutrient biomarkers were included in the analysis. The search resulted in 1504 articles. The inclusion and exclusion criteria limited the selection to thirty articles. Nineteen studies evaluated the usefulness of the dietary patterns, either a priori defined (thirteen studies), or defined by factor analysis (four studies) or by cluster analysis (two studies), but only nine of them tested their validity (four a priori defined and four a posteriori defined). Diet indices showed moderate to good validity results for measuring the adequacy of intakes for $\alpha$-carotene, $\beta$-carotene, vitamin $\mathrm{C}$, vitamin $\mathrm{B}_{6}, \mathrm{Ca}$, folic acid, $\mathrm{Fe}$ and $\mathrm{Mg}$. The factor analysis approach showed moderate to good validity correlations with the adequacy of intake of $\alpha$-carotene, $\beta$-carotene, lutein, lycopene, vitamin $\mathrm{C}$, vitamin $\mathrm{B}_{6}$ and folic acid. Vitamin $\mathrm{B}_{12}$ and vitamin $\mathrm{E}$ are the micronutrients with less probability of being adequately assessed with dietary patterns a priori or a posteriori defined. Diet indices are tools with fair to moderate validity to assess micronutrient intake adequacy.
\end{abstract}

Dietary pattern: Validity: Micronutrients: Adequacy assessment

Analyses of the relationship between food habits and health began by studying the role that specific nutrients may play in the etiopatogenesis of certain diseases. For instance, a folate deficiency was associated with a higher risk of neural tube defects. However, for certain diseases, the complexity of the relationships between dietary intake and the pathology cannot be attributed to a single nutrient but rather to multiple nutrients and foods. Thus, the correct exposure has to be measured to understand such a relationship, and not only nutrients but also foods, and the interaction between them, are of concern for this kind of evaluation. Food pattern analysis is then a key issue to investigate the linkages between nutrition and disease.

Diet scores or diet indices were the first methods used in nutritional epidemiology to assess the effect that a combination of nutrients or foods (not only a single nutrient) may exert on health. With that purpose two diet indices, the nutrient adequacy ratio (NAR) and the mean adequacy ratio (MAR), were defined to evaluate the overall dietary adequacy of individuals and population groups ${ }^{(1)}$. Diet indices, defined as a composite score of nutrients, foods or both, have been created based on previous nutrition knowledge for evaluating the adherence to prespecified guidelines or recommendations ${ }^{(2-6)}$. These patterns, as they are hypothesis oriented, are known as a priori defined. Another approach, the so-called $a$ posteriori approach, consists of defining food patterns once the dietary data are collected and using specific statistical analyses to identify the relevant actual food patterns of the study population. Such statistical analyses were first applied by Schwerin et al. ${ }^{(7)}$ (1982). From then on, several publications have used various statistical procedures, mainly factor analysis or cluster analysis to analyse dietary data and to empirically identify dietary patterns ${ }^{(3,5,7-11)}$.

Both a priori hypothesis-oriented diet indices and a posteriori defined patterns have been related to the incidence of health outcomes (hard clinical end points) and biomarkers in epidemiological or clinical studies. Some of these dietary patterns

\footnotetext{
Abbreviations: DDS, diet diversity score; DQI-R, diet quality index revised; FVS, food variety score; HEI, healthy eating index; MAR, mean adequacy ratio; MPA, mean probability of adequate; NN, number of nutrients.

On behalf of EURRECA's RA 1.1 'Intake Methods' members: Serra-Majem L (Coordinator), Cavelaars A, Dhonukshe-Rutten R, Doreste JL, Frost-Andersen L, García-Álvarez A, Glibetic M, De Groot L, Henríquez-Sánchez P, Naska A, Ngo J, Novakovic R, Ortiz-Andrellucchi A, Øverby NC, Gurinovic M, Pijls L, Ranic M, Ribas-Barba L, Ristic-Medic D, Román-Viñas B, Ruprich J, Saavedra-Santana P, Sánchez-Villegas A, Tabacchi G, Tepsic J, Trichopoulou A, van't Veer P, Vucic V, Wijnhoven TMA.

* Corresponding author: Lluís Serra-Majem, fax +3493 4034543, email lserra@dcc.ulpgc.es
} 
have been related to nutrient adequacy. This approach parallels that of a validation study, based on the rationale that if the classification of participants according to their adherence to the dietary pattern is able to ascertain whether or not they fail to meet the optimal nutrient intake, the use of the dietary pattern is sufficiently valid. The purpose of the present study was to review which methods that evaluate dietary patterns have been tested for their validity in measuring micronutrient intake adequacy.

\section{Material and methods}

We searched PubMed up to April 2008. The search strategy included both keywords and MesH terms. The keywords included were: 'diet quality', 'dietary pattern', 'food pattern', 'food groups', 'dietary diversity', 'dietary variety', 'diet score', 'diet index', 'nutrient adequate intake', 'nutrient inadequate intake', 'nutrient adequacy' and 'nutrient inadequacy'. And the MeSH terms were: 'factor analysis', 'statistical', 'cluster analysis', 'statistical analysis'.

We selected studies that analysed the correlation between food patterns (either defined a priori or a posteriori) and nutrient intake adequacy (assessed by the methods of the probability approach, the MAR, a cut-off point of the recommended reference intakes or other methods), or biochemical markers of intake. We identified studies that assessed the validity of the dietary patterns, in other words, studies that used two different methods of diet analysis (food frequency questionnaire, diet record and 24 hour recall) to derive dietary patterns and the adequacy of nutrient intake.

We excluded studies based on food balance sheet data, and studies that compared the dietary pattern against nutrient intake values for certain nutrients using the same instrument (nutrient intake data obtained from the same diet measurement tool that had been used to assess the dietary pattern). Studies that correlated dietary patterns with the incidence of health outcomes (hard clinical end points) were also excluded from the present analysis.

Articles were selected by reading the title and the abstract. The access to the full text of the article permitted a second stage of selection. Reference articles were also reviewed for potential inclusion.

\section{Results}

The initial Pubmed search retrieved 1504 articles. After applying the first selection criteria (title and abstract evaluation), fifty articles were obtained. The specific inclusion and exclusion criteria were applied and seventeen articles were finally included for the review. Thirteen more articles were identified by reviewing the references, thus obtaining a final selection of thirty articles.

Eight of the articles were reviews and three of them were methodological. Nineteen studies investigated the value of the dietary patterns assessed by diet index (thirteen studies), factor analysis (four studies) or cluster analysis (two studies). The methods used to evaluate nutrient intake adequacy were the probability approach in four studies, the MAR in five studies, a cut-off point of the reference intake values in one study and biomarkers of intake in five studies. Nine articles assessed validity comparing nutrient intake and the defined dietary pattern, both obtained from two different assessment tools (diet records were used as the standard to compare the dietary pattern).

Table 1 shows the results found for the studies in the search and Table 2 shows detailed information for micronutrient intake adequacy related to each dietary pattern, when the information was available.

\section{Diet indices}

Only five studies were identified as being a validation study and using two different methods to assess diet pattern and nutrient intake adequacy.

Newby ${ }^{(12)}$ studied a subsample of 127 men from the Health Professionals Follow-up study, to test the validity and reproducibility of the Diet Quality Index Revised (DQI-R). The individuals completed two FFQ, 1 year apart, and two 1 -week diet records. They also evaluated biochemical parameters to validate the index. The validity correlations for the DQI-R between each FFQ and the diet record (the effect of week to week variation in diet records was reduced statistically) were $r=0.66$ (FFQ1) and $r=0.72$ (FFQ2). The fruit score was the most strongly correlated component between the FFQ2 and the diet records $(r=0 \cdot 71)$. The association of $\mathrm{Ca}$ intake using the FFQ2 showed a correlation coefficient of $r=0.35$ against the DQI-R. The DQI-R was also compared with nutrient intake estimated by the diet records. The intake of folic acid, $\mathrm{Mg}, \mathrm{Fe}, \mathrm{Ca}$, vitamin $\mathrm{A}$, carotene, vitamins $\mathrm{B}_{6}$ and $\mathrm{C}$ was directly related to DQI-R scores. The correlation coefficient between the score for DQR-I from FFQ1 and FFQ2 was $r=0 \cdot 72$. They concluded that the DQR-I was reasonably reproducible over time and reasonably valid compared with plasma biomarkers and compared with food record-derived nutrient intakes.

Torheim et al. ${ }^{(13)}$ evaluated the validity of three indices of diet quality calculated from a FFQ in two different population groups (seventy-five and seventy individuals, respectively) from Western Mali. They used a 2-d weighed record as a validation tool. The indices were the Food Variety Score (FVS), the Diet Diversity Score (DDS) and the MAR. They found Spearman correlation coefficients of $r=0 \cdot 3$ and $0 \cdot 15$ (population group A and population group B) between FVS from the FFQ and the two weighed records; $r=0.20$ (for both population groups) between the DDS from the FFQ and the two weighed records; and $r=0.4$ (population group A) and $r=0.49$ (population group B) between the MAR from FFQ and two weighed records. They also compared the FVS and the DDS against the adequacy of the intake evaluated by the MAR from the two weighed records. They found correlation coefficients of $r=0.36$ and 0.24 (group A and B) between FVS and MAR, and $r=0.35$ (study A) and $r=0.29$ (study B) between DDS and MAR. They found different correlation coefficients for males and females, and they concluded that both indices were relatively good indicators for nutrient adequacy among males.

In another study in a sample of 340 women, Hann et al. ${ }^{(14)}$ showed data for validating the Healthy Eating Index (HEI) score against plasma biomarkers. Dietary data was assessed using a 3-d food record. They showed that higher HEI scores were associated with higher plasma concentrations of certain carotenoids ( $\alpha$-carotene, $r=0.41 ; \beta$-carotene 
Table 1. Studies assessing the validity of diet pattern to test nutrient intake adequacy

\begin{tabular}{|c|c|c|c|c|c|}
\hline & Sample & Diet data & Diet pattern & Validation tool & Results \\
\hline \multicolumn{6}{|l|}{ Diet indices } \\
\hline $\begin{array}{l}\text { Kennedy } \\
\text { et al. }{ }^{(17)}\end{array}$ & 2805 (24-71 months) & $1-24 \mathrm{HR}$ & DDS & MPA (eleven nutrients) & DDS/MPA, $r=0.36$ ( 0.44 for DDS10 g minimum intake) \\
\hline $\begin{array}{l}\text { Mirmiran } \\
\text { et al. }{ }^{(18)}\end{array}$ & $286 \uparrow(19-80$ years $)$ & $2-24 \mathrm{HR}$ & DDS & MPA (fourteen nutrients) & DDS/MPA, $r=0.6$ ( 0.43 adjusted for energy) \\
\hline $\begin{array}{l}\text { Steyn } \\
\text { et al. }{ }^{(19)}\end{array}$ & 2200 (1-8.9 years) & $24 \mathrm{HR}$ & FVS, DDS & MAR (eleven nutrients) & FVS/MAR, $r=0.726 ;$ DDS/MAR $r=0.657$ \\
\hline $\begin{array}{l}\text { Mirmiran } \\
\text { et al. }\end{array}$ & 304 (10-18 years) & $2-24 \mathrm{HR}$ & DDS & MAR (twelve nutrients) & DDS/MAR, $r=0.42$ \\
\hline $\begin{array}{l}\text { Foote } \\
\text { et al. }\end{array}$ & $49690^{7} 4800$ 우 & $1-24 \mathrm{HR}$ & $\mathrm{HEI}$ & MPA (fifteen nutrients) & 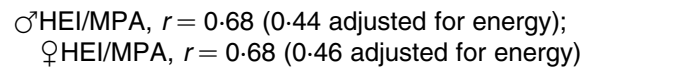 \\
\hline $\begin{array}{l}\text { Weinstein } \\
\text { et al. }{ }^{(15)}\end{array}$ & $16467 \geq 17$ years & $24 \mathrm{HR}$ & $\mathrm{HEI}$ & Biomarkers & $\begin{array}{l}\mathrm{HEI} / \text { serum folate }(r=0.25), \mathrm{HEI} / \mathrm{RBCF}(r=0.27), \mathrm{HEI} / \mathrm{vit} \mathrm{C} \\
\quad(r=0.30), \mathrm{HEI} / \mathrm{vit} \mathrm{E}(r=0 \cdot 21), \mathrm{HEI} / \alpha \text {-carotene } \\
(r=0.27), \mathrm{HEI} / \beta-\text { carotene }(r=0.21), \mathrm{HEI} / \beta \text {-cryptoxanthin } \\
(r=0.24) \text { and HEI/lutein }(r=0.17) \text {. No correlations for } \\
\text { HEl and cholesterol, triglyceride, vitamin D, ferritin, } \\
\text { selenium or total Ca level }\end{array}$ \\
\hline $\begin{array}{l}\text { Newby } \\
\text { et al. }{ }^{(12)}\end{array}$ & $127 \sigma^{7}(40-75$ years $)$ & Two-FFQ & DQI-R & $\begin{array}{l}\text { DQR-I and food intake from two } \\
\text { 1-week DR and biomarkers }\end{array}$ & $\begin{array}{l}\text { DQI-R(FFQ)/DQI-R(DR), } r=0.66 \text { (FFQ1) and } r=0.72 \\
\text { (FFQ2). DQR-I(FFQ1)/DQR-I(FFQ2), } 1 \text { year apart } \\
r=0.72\end{array}$ \\
\hline $\begin{array}{l}\text { Serra- } \\
\text { Majem } \\
\text { et al. }{ }^{(22)}\end{array}$ & 3166 (6-24 years) & $2-24 \mathrm{HR}$ & KIDMED & $<$ two-third RDI & $\begin{array}{l}\text { The percentage of inadequacy declines with increasing } \\
\text { index scores for } \mathrm{Ca} \text {, iron (in females), } \mathrm{Mg} \text {, vitamin } \mathrm{B} 6 \\
\text { (excluding males aged } 6-14 \mathrm{y} \text { ), vitamins } \mathrm{C} \text { and } \mathrm{A} \\
\text { (in females). }\end{array}$ \\
\hline \multirow{2}{*}{$\begin{array}{l}\text { Torheim } \\
\text { et al. }{ }^{(13)}\end{array}$} & $48+27 \sigma^{7}(15-59$ years $)$ & & & & \\
\hline & $34+360^{7}$ (15-45 years) & FFQ & DDS, FVS, MAR & $\begin{array}{l}\text { DDS. FVS. MAR calculated from } \\
\text { a } 2 d \text { WR and MAR from the } \\
\text { two WR }\end{array}$ & $\begin{array}{l}\text { FVS(FFQ)/FVS(WR), } r=0.3 \text { and } r=0.15 \text { (group A and } \\
\text { group B); DDS(FFQ)/DDS(WR), } r=0.20 \text { (for both } \\
\text { groups); MAR(FFQ)/MAR(WR), } r=0.4 \text { (group A) and } \\
r=0.49 \text { (group B); FVS/MAR } r=0.36 \text { and } r=0.24 \\
\text { (group A and B); DDS/MAR } r=0.35 \text { (group A) and } \\
r=0.29 \text { (group B) }\end{array}$ \\
\hline $\begin{array}{l}\text { Hann } \\
\text { et al. }{ }^{(14)}\end{array}$ & 340 ㅇ $(21-80$ years $)$ & $3 d \mathrm{DR}$ & HEI & Biomarkers & $\begin{array}{c}>\mathrm{HEI}=>\text { plasma concentrations ( } \alpha \text {-carotene, } r=0.40 \\
\beta \text {-carotene } r=0.28 ; \beta \text {-cryptoxanthin, } r=0.41 \text {; and } \\
\text { lutein, } r=0.23 \text { ) and vitamin } \mathrm{C}(r=0.26)\end{array}$ \\
\hline $\begin{array}{l}\text { Gerber } \\
\text { et al. }{ }^{(16)}\end{array}$ & 150 (20-74 years) & FFQ & DQI & Biomarkers & $\begin{array}{l}\text { DQI positively related to } n-3 \text { FA (EPA and DHA) and } \\
\text { inversely associated to cholesterol }\end{array}$ \\
\hline $\begin{array}{l}\text { Dubois } \\
\text { et al. }\end{array}$ & 2103 (18-74 years) & $24 \mathrm{HR}$ & DQI, HEI, HDI & MAR & $\begin{array}{l}\text { HEI/MAR, } r=0.287 ; \text { DQI/MAR, } r=0.001 ; \mathrm{HDI} / \mathrm{MAR}, \\
\quad r=0.079\end{array}$ \\
\hline $\begin{array}{l}\text { Hatløy } \\
\text { et al. } 24)\end{array}$ & 77 (13-58 months) & $\begin{array}{l}\text { Three (or two) } \\
\text { WR }\end{array}$ & FVS, DDS & MPA (ten nutrients) & FVS/MAR, $r=0.33 ;$ DDS/MAR, $r=0.39$ \\
\hline
\end{tabular}


Table 1. Continued

\begin{tabular}{|c|c|c|c|c|c|}
\hline & Sample & Diet data & Diet pattern & Validation tool & Results \\
\hline \multicolumn{6}{|l|}{ Factor analysis } \\
\hline $\begin{array}{l}\text { Newby } \\
\text { et al. }{ }^{(29)}\end{array}$ & 33840 우 & $\begin{array}{l}\text { Two-FFQ } 10 \text { y } \\
\text { apart }\end{array}$ & HP, WP, DP, SP & FFQ 10 y apart & reproducibility from $r=0.27$ to $r=0.54$ \\
\hline $\begin{array}{l}\text { Khani } \\
\text { et al. }{ }^{(26)}\end{array}$ & $\begin{array}{l}362 \text { (validity) } 265 \text { q } \\
\quad \text { (reproducibility) } \\
\quad \text { (40-74 years) }\end{array}$ & $\begin{array}{l}\text { Two-FFQ and } \\
\text { four 1-week } \\
\text { DWR }\end{array}$ & $H P, W P, D P$ & FA applied to four 1-week DR & $\begin{array}{l}\text { FFQ/DR, } r=0.47 \text {; HP, } r=0.41 \text {; WP, } r=0.73 \text { DP. Repro- } \\
\text { ducibility FFQ1/FFQ2, } r=0.63 \text { (HP), } r=0.68 \text { (WP) and } \\
r=0.73 \text { (DP) }\end{array}$ \\
\hline Hu et al. ${ }^{(25)}$ & $127 O^{7}$ ( $40-75$ years $)$ & $\begin{array}{l}\text { Two-FFQ } 1 \text { y } \\
\text { apart/two } \\
\text { 1-week DR }\end{array}$ & PP, WP & $\begin{array}{l}\text { FA applied to two 1-week DR } \\
\text { and biomarkers }\end{array}$ & $\begin{array}{l}\text { FFQ/DR PP, } r=0.45 \text { and FFQ/DR WP } r=0.74 \text {; PP/ } \alpha \text {-car- } \\
\text { otene from } r=0.29 \text { (FFQ1) to } r=0.39 \text { (FFQ2), PP/ } \beta \text { - } \\
\text { carotene, } r=0.23 \text { (FFQ1) to } r=0.37 \text { (FFQ2); PP/lyco- } \\
\text { pene, } r=0.28 \text { (FFQ1) to } r=0.31 \text { (FFQ2); and PP/lutein } \\
\text { from } r=0.33 \text { (FFQ1) to } r=0.33 \text { (FFQ2). Reproducibil- } \\
\text { ity: FFQ1/FFQ2, } r=0.7 \text { for the PP; FFQ1/FFQ2, } \\
r=0.67 \text { for the WP }\end{array}$ \\
\hline $\begin{array}{l}\text { Beaudry } \\
\text { et al. }\end{array}$ & 2118 (18-74 years) & $1-24 \mathrm{HR}$ & HEDP, TP, H-CP & $\begin{array}{l}\text { Indices of nutritional adequacy } \\
\text { (GS; NN; NN66) }\end{array}$ & $\begin{array}{l}\mathrm{HEDP} / \mathrm{GS}=0.031, \mathrm{HEDP} / \mathrm{NN}=0.05 \\
\mathrm{HEDP} / \mathrm{NN} 66=0.041, \mathrm{TP} / \mathrm{GS}=0.4, \mathrm{TP} / \mathrm{NN}=0.042 \\
\mathrm{TP} / \mathrm{NN} 66=0.37, \mathrm{H}-\mathrm{CP} / \mathrm{GS}=0.33, \mathrm{H}-\mathrm{CP} / \mathrm{NN}=0.34 \\
\mathrm{H}-\mathrm{CP} / \mathrm{NN} 66=0.30\end{array}$ \\
\hline \multicolumn{6}{|r|}{ 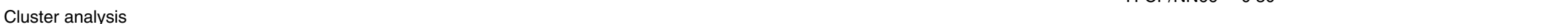 } \\
\hline $\begin{array}{l}\text { Quatromoni } \\
\text { et al. }{ }^{(32)}\end{array}$ & 1828 ㅇ & FFQ & $\begin{array}{l}\text { Heart healthy, light eating, wine and } \\
\text { moderate eating, high fat, empty } \\
\text { energy }\end{array}$ & $\begin{array}{l}\text { Nutrient rank risk calculated } \\
\text { from a } 3 \mathrm{~d} D R\end{array}$ & $\begin{array}{l}\text { Heart-healthy pattern showed most desirable ranks in } \\
\text { terms of } \mathrm{Ca} \text {, vitamins } \mathrm{C}, \mathrm{B}_{6} \text { and } \mathrm{E} \text {, folate and } \beta \text {-carotene } \\
\text { intakes }\end{array}$ \\
\hline $\begin{array}{l}\text { Millen } \\
\text { et al. }\end{array}$ & 1828 운 & FFQ & $\begin{array}{l}\text { Heart healthy, light eating, wine and } \\
\text { moderate eating, high fat, empty } \\
\text { energy }\end{array}$ & $\begin{array}{l}\text { Nutrient rank risk calculated } \\
\text { from a } 3 \mathrm{~d} D R\end{array}$ & $\begin{array}{l}\text { Heart-healthy pattern showed higher intakes of protective } \\
\text { nutrients (Ca, vitamins } \mathrm{C}, \mathrm{B}_{6} \text { and } \mathrm{E} \text {, folate and } \\
\beta \text {-carotene intakes) }\end{array}$ \\
\hline
\end{tabular}

24 HR, 24 hour recall; DDS, dietary diversity score; MPA, mean probability approach; FVS, food variety score; MAR, mean adequacy ratio; HEI, healthy eating index; RBCF, red blood cell folate; FFQ, Food Frequency Questionnaire; DQI-R, Diet Quality Index Revised; DR, dietary record; RDI, Recommended Dietary Intake; WR, weighed record; HDI, healthy diet indicator; HP, healthy pattern; WP, western pattern; DP, drinker pattern; SP, sweets patterns; FA, factor analysis; PP, prudent pattern; HEDP, health energy density pattern; TP, traditional pattern; H-CP, health-conscious pattern; GS, global score; NN, number of nutrients for which intake is equal to or better than recommended levels; NN66, number of nutrients for which intake is equal to or better than $66 \%$. 
WS British Journal of Nutrition

Table 2. Correlation coefficient between nutrient adequacy and diet pattern methods

\begin{tabular}{|c|c|c|c|c|c|c|c|c|c|c|c|c|c|}
\hline & & Vitamin A & Carotene & $\alpha$-Carotene & $\beta$-Carotene & Lycopene & Lutein & $\beta$-Cryp & nthin & Vitamin C & Thiamin & Riboflavin & Niacin \\
\hline DDS & & & & & & & & & & & & & \\
\hline Hann et al. ${ }^{(14)}$ & & & & $0.41^{*}$ & $0.3^{*}$ & -0.02 & $0.24^{*}$ & 0. & & $0.33^{\star}$ & & & \\
\hline Kenedy et al. ${ }^{(17)}$ & & 0.43 & & & & & & & & 0.29 & 0.31 & 0.4 & 0.23 \\
\hline & & 0.32 & & & & & & & & 0.44 & & 0.33 & \\
\hline Mirmiran et al. ${ }^{(18)}$ & & 0.32 & & & & & & & & 0.44 & & 0.44 & \\
\hline Steyn et al. ${ }^{(19)}$ & & 0.19 & & & & & & & & 0.15 & 0.22 & 0.36 & 0.49 \\
\hline Mirmiran et al. ${ }^{(20)}$ & & 0.26 & & & & & & & & $0 \cdot 14$ & 0.05 & $0 \cdot 16$ & \\
\hline Hatløy et al. ${ }^{(24)}$ & & 0.3 & & & & & & & & 0.29 & & & \\
\hline $\mathrm{HEI}$ & & & & & & & & & & & & & \\
\hline Weinstein et al. ${ }^{(15)}$ & & $0.05^{\star}$ & & $0.20^{\star}$ & $0.12^{*}$ & $0.03^{*}$ & $0.12^{*}$ & & & $0 \cdot 21^{*}$ & & & \\
\hline Foote et al. ${ }^{(21)}$ & $0^{\prime \prime}$ & 0.29 & & & & & & & & & & & \\
\hline DQI-R & q & 0.27 & & & & & & & & & & & \\
\hline Newby et al. ${ }^{(12)}$ & & 0.22 & 0.26 & $0.43^{*}$ & $0.35^{*}$ & $0.17^{*}$ & $0.31^{*}$ & & & 0.59 & & & \\
\hline FVS & & & & & & & & & & & & & \\
\hline Steyn et al. ${ }^{(19)}$ & & 0.19 & & & & & & & & 0.18 & 0.27 & 0.42 & 0.56 \\
\hline Hatløy et al. ${ }^{(24)}$ & & 0.27 & & & & & & & & 0.38 & & & \\
\hline Factor analysis & & & & & & & & & & & & & \\
\hline Hu et al. ${ }^{(25)} \|$ & & 0.09 & 0.27 & 0.29 & 0.23 & 0.28 & 0.33 & & & & & & \\
\hline Newby et al. ${ }^{(29)} \S \|$ & First & & & & 0.55 & & & & & $0 \cdot 6$ & & & \\
\hline & second & & & & 0.62 & & & & & $0 \cdot 78$ & & & \\
\hline & & Vitamin B & & Vitamin $B_{12}$ & Vitamin E & $\mathrm{Ca}$ & Folate & $\mathrm{Zn}$ & $\mathrm{Fe}$ & K & $P$ & $\mathrm{Mg}$ & $\mathrm{Na}$ \\
\hline DDS & & & & & & & & & & & & & \\
\hline Hann et al. ${ }^{(14)}$ & & & & & & 0.26 & & & & & & & \\
\hline Kenedy et al. ${ }^{(17)}$ & & 0.13 & & 0.06 & & 0.02 & 0.35 & 0.11 & 0.15 & & & & \\
\hline & & & & & & & & & & 0.19 & 0.32 & & \\
\hline Mirmiran et al. ${ }^{(18)}$ & & 0.22 & & 0.24 & & 0.54 & & 0.24 & 0.24 & 0.39 & 0.23 & & \\
\hline Steyn et al. ${ }^{(19)}$ & & 0.48 & & 0.13 & & 0.25 & 0.29 & 0.40 & 0.26 & & & & \\
\hline Mirmiran et al. ${ }^{(20)}$ & & & & & & 0.35 & & 0.32 & 0.03 & 0.33 & 0.29 & 0.29 & \\
\hline Hatløy et al. ${ }^{(24)}$ & & & & & & & & & & & & & \\
\hline $\mathrm{HEI}$ & & & & & & & & & & & & & \\
\hline Weinstein et al. ${ }^{(15)}$ & & & & $0.01^{*}$ & $0.13^{*}$ & & $0.15^{*}$ & & & & & & \\
\hline Foote et al. ${ }^{(21)}$ & $0^{x}$ & & & & & 0.67 & & & & & & & \\
\hline & q & & & & & 0.7 & & & & & & & \\
\hline DQI-R & & & & & & & & & & & & & \\
\hline Newby et al. ${ }^{(12)}$ & & 0.49 & & & $0 \cdot 16$ & $0.35 \dagger$ & 0.50 & & $0.36 \neq$ & & & 0.56 & -0.13 \\
\hline FVS & & & & & & & & & & & & & \\
\hline Steyn et al. ${ }^{(19)}$ & & 0.58 & & $0 \cdot 11$ & & 0.29 & 0.34 & 0.45 & 0.29 & & & & \\
\hline Hatløy et al. ${ }^{(24)}$ & & & & & & & & & & & & & \\
\hline Factor analysis & & & & & & & & & & & & & \\
\hline Hu et al. ${ }^{(25)} \|$ & & & & & 0.12 & & & & & & & & \\
\hline Newby et al. ${ }^{(29)} \S \|$ & First & 0.46 & & 0.21 & & & 0.64 & & & & & & \\
\hline & second & 0.63 & & 0.02 & & & 0.73 & & & & & & \\
\hline
\end{tabular}

DDS, diet diversity score; HEI, healthy eating index; DQI-R, diet quality index revised; FVS, food variety score.

* Biochemical measurement.

$r=0.54$ when comparing DQI-R and prevalence of adequacy

$r=0.06$ when comparing DQI-R and prevalence of adequacy

$\S$ Comparison against nutrient intake.

Dattern derived from data from FFQ and biochemical data. 
$r=0.30 ; \beta$-cryptoxanthin, $r=0.40$; and lutein, $r=0 \cdot 24)$ and vitamin $\mathrm{C}(r=0 \cdot 33)$

Data from the Third National Health and Nutrition Examination Survey were used to relate nutritional biomarkers with the HEI ${ }^{(15)}$. The results showed a positive correlation between HEI and serum folate $(r=0 \cdot 25)$ and red blood cell folate $(r=0 \cdot 27)$, serum vitamins $\mathrm{C}(r=0 \cdot 30), \mathrm{E}(r=0 \cdot 21), \alpha$-carotene $(r=0 \cdot 27), \quad \beta$-carotene $(r=0 \cdot 21), \quad \beta$-cryptoxanthin $(r=0 \cdot 24)$ and lutein $(r=0 \cdot 17)$. No correlations were found between the HEI score and cholesterol, triglyceride, vitamin D, ferritin, Se or total Ca level.

Other studies have associated diet indices with plasma biomarkers. Gerber et al. ${ }^{(16)}$ found that an adaptation of DQI to French dietary habits was positively related to omega 3 fatty acids (EPA and DHA) and inversely associated to cholesterol in a sample of 147 volunteers from southern France. Nutrition data were obtained with a FFQ.

The following studies do not use a validation tool, but correlated the diet patterns under study against the measurement of nutrient intake adequacy using the same dietary data collection method.

In a group of Filipino children, Kennedy et al. ${ }^{(17)}$ showed that the DDS was a valid tool to predict adequate intake. The probability approach was used to calculate the adequacy of intake for eleven nutrients and a mean probability of adequate nutrient intake (MPA) was calculated. The Pearson's correlation between DDS and MPA was significant $(r=0.36)$ and improved to 0.44 when they calculated a DDS applying a $10 \mathrm{~g}$ minimum intake for all food groups (except fats and oils). The correlation between the DDS and the MPA was significant for nine nutrients (vitamin A, vitamin $\mathrm{C}$, thiamin, riboflavin, niacin, vitamin $\mathrm{B}_{6}$, folic acid, absorbed $\mathrm{Zn}$ and absorbed $\mathrm{Fe}$ ).

Mirmiran $^{(18)}$ studied the appropriateness of DDS to assess nutrient adequacy in a population of Iranian women. They calculated DDS with a set of five groups. The probability of adequacy for fourteen nutrients and MPA was calculated. The cereals diversity score correlated with the probability of adequacy for vitamin $\mathrm{B}_{2}$. The vegetable diversity score correlated with intake adequacy for vitamins $\mathrm{A}, \mathrm{C}$ and $\mathrm{K}$. The fruit diversity score correlated with the probability of adequacy for vitamins $\mathrm{A}, \mathrm{C}$ and $\mathrm{K}$. The dairy diversity score correlated with $\mathrm{Ca}, \mathrm{P}$ and vitamin $\mathrm{B}_{2}$ and $\mathrm{Zn}$ adequacies. The meat diversity score correlated with the probability of adequacy for vitamins $\mathrm{B}_{6}$ and $\mathrm{B}_{12}, \mathrm{Fe}$ and $\mathrm{P}$. The correlation between DDS and the MPA was $r=0.6(r=0.43$ when adjusted for energy intake).

Steyn et al. ${ }^{(19)}$ assessed whether the FVS and the DDS were good indicators of nutrient intake adequacy among a sample of 2200 children aged 1-8 years old. Dietary data were obtained with a 24 hour recall and nutrient intake adequacy was assessed calculating the MAR for eleven nutrients. They obtained a high correlation between FVS and MAR $(r=0.726)$ and DDS and MAR $(r=0.657)$. Both the FVS and the DDS were correlated with the adequacy of vitamins $\mathrm{A}, \mathrm{B}_{6}, \mathrm{~B}_{12}, \mathrm{C}$, and $\mathrm{Ca}$, folic acid, $\mathrm{Fe}$, niacin, riboflavin, thiamin and $\mathrm{Zn}$ for all subjects.

In addition, Mirmiran et al. ${ }^{(20)}$ evaluated the DDS as an indicator of nutritional adequacy among 304 adolescents from Tehran. They used the MAR to assess nutrient intake adequacy and found a correlation coefficient between DDS and MAR of $r=0.42$. The MAR reflected the nutrient adequacy ratio of twelve nutrients (vitamin $\mathrm{A}$, riboflavin, thiamin, vitamin $\mathrm{C}, \mathrm{Ca}, \mathrm{Fe}, \mathrm{Zn}, \mathrm{P}, \mathrm{Mg}$, protein, $\mathrm{K}$ and fat). The correlation between DDS and the Nutrient Adequacy Ratio was significant for vitamin $\mathrm{A}$, riboflavin, $\mathrm{Zn}, \mathrm{Ca}, \mathrm{K}, \mathrm{P}$ and $\mathrm{Mg}$.

Foote et al. ${ }^{(21)}$ assessed the association between diet variety, as measured with a commodity-based definition similar to the HEI and nutrient adequacy. The sample came from the Continuing Survey of Food Intakes by Individuals (94-6). They calculated the probability of adequacy for fifteen nutrients and created an MPA. The results showed that total dietary variety was correlated with the mean probability of adequacy in both men $(r=0.44)$ and women $(r=0.46)$, after adjusting for energy intake. Dairy diversity score correlated with $\mathrm{Ca}$ and vitamin $\mathrm{A}$. The cereals diversity score correlated with the probability of adequacy for folate and $\mathrm{Mg}$. The fruit diversity score correlated with the probability of adequacy for vitamins $\mathrm{A}$ and $\mathrm{C}$.

Serra-Majem et al. ${ }^{(22)}$ compared the nutritional status of Spanish children against a Mediterranean diet score (KIDMED index). The nutrient intake adequacy was assessed as the percentage of population with intakes below two-thirds of the recommended nutrient intakes. The higher the KIDMED index score, the lower the prevalence of inadequacy for $\mathrm{Ca}, \mathrm{Fe}$ (in females), $\mathrm{Mg}$, vitamin $\mathrm{B}_{6}$ (excluding males aged 6-14) and vitamins $\mathrm{C}$ and A (in females).

Dubois $^{(23)}$ assessed the appropriateness of three methods of measuring diet quality (DQI, HEI and Healthy Diet Indicator $=\mathrm{HDI}$ ) to evaluate adherence to the Canadian recommendations. The study was developed with data from the Québec Nutrition Survey (2103 individuals that completed a 24 hour recall). The results showed that the HEI was the method having a higher correlation coefficient when compared with the MAR $(r=0 \cdot 287)$.

Hatløy et al. (24) also used the MAR as an indicator of nutrient adequacy to validate FVS and DDS in a sample of 77 children, 13-58 months of age in Mali. The diet was assessed with a 2 or 3 -d weighed record. They found positive correlation coefficients between FVS and MAR $(r=0 \cdot 33)$ and DDS and MAR $(r=0 \cdot 39)$. Both the FVS and the DDS correlated with the nutrient adequacy ratio of vitamin $\mathrm{C}$ and vitamin A.

\section{Factor analysis}

There is scarce data on the validity and reproducibility of the factor analysis method. Only two studies reported validation data related to diet patterns derived from factor analysis.

Hu et al. ${ }^{(25)}$ analysed the reproducibility and validity of two dietary patterns defined by factor analysis, the Prudent diet and the Western diet, in a group of 157 men participating in the Health Professionals' Follow-up study. They compared the consistency of the dietary patterns derived from the two FFQ, obtained in a 1 year interval, and diet records (two 7-d diet records). Good correlation coefficients were observed (a coefficient of $r=0.7$ for the prudent pattern and $r=0.67$ for the Western pattern when assessed by the two FFQ). When they compared the dietary pattern defined from the two FFQ against that defined by diet records, they found correlation coefficients of $r=0.45$ for the Prudent pattern and $r=0.74$ for the Western pattern. They also assessed the 
validity of the defined dietary patterns by comparing the dietary patterns with computed nutrients obtained from the diet record and with plasma biochemical concentrations. The results showed moderate correlation values between the dietary patterns and certain nutrient intakes (fibre, $\mathrm{Mg}, \mathrm{K}$, folic acid, vitamin $\mathrm{B}_{6}$ and carotenes for the Prudent pattern, and total fat and saturated fat for the Western diet). The Pearson correlation coefficient between the Prudent pattern and plasma concentration of biomarkers ranged from $r=0.29$ (FFQ1) to $r=0.39$ (FFQ2) for $\alpha$-carotene; from $r=0.23$ (FFQ1) to $r=0.37$ (FFQ2) for $\beta$-carotene; from $r=0.28$ (FFQ1) to $r=0.31$ (FFQ2) for lycopene; and from $r=0.33$ (FFQ1) to $r=0.33$ (FFQ2) for lutein. The dietary pattern defined from the diet record showed better correlation values with the blood measurements than the ones defined from the FFQ.

Khani et al. ${ }^{(26)}$ studied the validity and reproducibility of major dietary patterns in Swedish women from the Swedish Mammography Cohort. They defined three different dietary patterns by factor analysis (Healthy, Western and Drinker) and tested their reproducibility. Patterns were compared, as defined from two FFQ administered 1 year apart. They obtained coefficients of reproducibility of $r=0.63$ (Healthy pattern), $r=0.68$ (Western pattern) and $r=0.73$ (Drinker pattern). The information obtained from four 7-d diet records was used as a gold standard to validate the dietary patterns. Correlation coefficients of $r=0.47$ for the Healthy pattern, $r=0.41$ for the Western and $r=0.73$ for the Drinker profile were obtained.

The following studies correlated dietary patterns based on factor analysis against nutrient intake adequacy using dietary data obtained from the same instrument.

Beaudry et al. ${ }^{(27)}$ evaluated the dietary pattern of 2118 adults participating in the Canadian Provincial Nutrition Survey. They defined three patterns (high-energy density, traditional and health conscious) and correlated it with three scores (global score, energy score, number of nutrients (NN) for which intake was equal to or better than the recommended level and the $\mathrm{NN}$ for which intake was equal to or better than $66 \%$ of recommended level (NN66)). These have been defined previously by the same authors to evaluate nutrient adequacy $^{(28)}$. The Health-conscious pattern was positively correlated with each of the nutrient adequacy scores defined, with Kendall's $\tau$-b correlation coefficient of 0.33 against global score, $0 \cdot 22$ against energy score and 0.34 and $0 \cdot 30$ against NN and NN66, respectively. The Traditional pattern also correlated with the nutrient adequacy scores $(0.40$ between the pattern and the global score, 0.42 between the pattern and NN and 0.37 between the pattern and NN66).

Newby ${ }^{(29)}$ tested the long-term stability and reproducibility of dietary patterns defined by confirmatory factor analysis among a sample of Swedish women. Correlation values for food group intake across 10 year intervals were moderate and ranged from $r=0.27$ to 0.54 for the four patterns defined. The Healthy pattern was strongly correlated with nutritional intakes of vitamin $B_{6}$, folic acid, vitamin $C$ and $\beta$-carotene.

In another study that examined the stability of dietary patterns in a group of ninety-four women from the Southampton Women's Survey, Borland et al. ${ }^{(30)}$ assessed the reproducibility of dietary scores that were analysed 2 years apart. A Bland-Altman plot of the differences between scores obtained on the two occasions was also calculated. Two dietary patterns were defined using principal component analysis calculated from the dietary data derived from a FFQ, the 'Prudent' and 'High-energy patterns'. They showed Spearman correlation coefficients of 0.81 and 0.64 between the initial and repeated score for the prudent and high energy patterns, respectively.

\section{Cluster analysis}

A validation study for dietary pattern as defined by cluster analysis was published by Millen et al. ${ }^{(31)}$ and Quatromoni et al. ${ }^{(32)}$. The sample came from 1828 women participating in the Framingham Offspring-Spouse study. They correlated the five dietary patterns derived from dietary data obtained from a FFQ (Heart Healthy, Light eating, Wine and Moderate eating, High fat and Empty energy) against a nutrient rank risk. The nutrient rank risk was calculated from nutrient intake data obtained from a 3-d dietary record, and it represented the independent criteria for which to assess the internal validity of dietary patterns. They ranked nutrient intake among all women according to a desirable nutrient intake level as protective or risky in terms of chronic disease prevention. A mean rank was calculated as the average of rankings from nineteen individual nutrient variables for each woman. The results showed that dietary patterns were associated with differences in nutrient intake profiles. For instance, the Heart-healthy pattern was associated with the most desirable overall rank, and with the lowest ranks of intake for protein, total, saturated and monounsaturated fat, carbohydrate, fibre, $\mathrm{Ca}$, vitamins $\mathrm{C}, \mathrm{B}_{6}$ and $\mathrm{E}$, folic acid and $\beta$-carotene. Women in the Empty energy cluster consumed low-nutrient quality diets, with a higher intake of total fat and energy, and lower intakes of vitamins, fibre, protein and alcohol.

\section{Discussion}

Two approaches can be used to define dietary patterns: one is an a priori or theoretical approach that consists of the definition of certain scores or indices ${ }^{(2-6,33)}$. The second comprises an empirical or an a posteriori definition; it is defined after dietary data collection and is based on statistical calculations $^{(3,5,7-9)}$.

The a priori approach. Defined by Waijers et al. ${ }^{(4)}$ as 'Nutritional variables considered to be important to health that are quantified and summed to provide an overall measure of diet quality'. These score-based approaches are mostly constructed following certain dietary recommendations, and the inclusion of the selected nutrients or foods depends on their presence in the guidelines utilised to define the score (and to a certain degree, it also depends on the investigator's judgement).

The construction of dietary indices may be based on nutrients only, foods or food groups and a combination of nutrients and foods ${ }^{(2)}$. The data are grouped according to predefined cut-off points. The newly defined groups are assigned values, which are then summed up to obtain a measure of diet quality or a diet score. Recent reviews of Waijers et $a .^{(4)}$ and Arvaniti et al. ${ }^{(6)}$ have reported more than twenty currently existing indices.

The main advantage of the a priori approach is its generalisability, i.e. that it can be applied to multiple populations. On the other hand, several inconveniencies arise when analysing 
data: their definition might rely on the investigator's subjectivity, and they are based on dietary recommendations, which have been defined for certain populations and may not be applicable to others ${ }^{(2,4,6)}$.

The a posteriori approach or exploratory approach. Data reduction techniques use between-food group correlations to reduce dietary data collected from FFQ, 24 hour recalls or diet records into smaller sets of variables to define dietary patterns. Three techniques are used for this purpose: factor analysis, cluster analysis and reduced-rank regression.

Factor analysis. Factor analysis is a procedure that aggregates and reduces dietary data into food groups according to an intercorrelation between dietary items ${ }^{(34)}$. It includes both principal component analysis and confirmatory factor analysis.

As Martínez et al. ${ }^{(34)}$ argue, the application of factor analysis to dietary data, although being a mathematical model, is pragmatic and atheoretical. They cited several subjective decisions that must be made when defining the dietary pattern: which variables will be included in the analysis to construct factors, what level will be used to decide whether a variable may contribute to a factor and finally, what label to apply to the given factor. Such decisions can lead to erroneous conclusions. For instance, when choosing the variables to analyse, unrelated variables may be included in the analysis when other variables were excluded so as to simplify the analysis.

Exploratory factor analysis is used when an a priori hypothesis exists about the factor structure. As such, its advantage is ${ }^{(5,29)}$ that it reduces some of the subjectivity associated with the exploratory procedure and can be applied in different population samples ${ }^{(35)}$.

Cluster analysis. The cluster analysis is a multivariate statistical approach that unifies individuals (cluster) that share similar observations for a certain number of variables. Individuals in a cluster have similarities between them (i.e. similar diets) and disparities with individuals from another cluster.

This method also includes a certain amount of subjectivity: the choice of which variables will be used, or what level of significance (variables to include in the analysis and number of factors to be included) will be applied ${ }^{(5)}$.

Reduced-rank regression or maximum redundancy analysis. Hoffman et al. ${ }^{(36)}$ introduced this statistical method to analyse dietary patterns. It is a statistical reduction technique that works with two different sets of variables: predictors and responses. Reduced-rank regression identifies linear functions of predictors that explain as much response variation as possible. The approach ensures that a change in reduced-rank regression pattern score results in a change in the related variable (biomarker or health outcome), which is generally associated with a decrease or increase in the health risk under study. As with other a posteriori approaches, it is difficult to assess whether the dietary pattern can be applied in two different population samples. Theoretically, if the weights and food variables used to calculate reduced-rank regression and to define a dietary pattern can be applied to another population sample, the results would then be comparable ${ }^{(37)}$.

\section{Validity and reproducibility of dietary patterns}

The usefulness of any method will depend upon its validity and reproducibility. Validity is defined as the degree to which a measurement is a true and accurate measure of what it pretends to measure. Dietary patterns are defined mainly for assessing eating behaviour and for relating intake to disease or health outcomes. The measurement of the validity of a method that assesses dietary patterns should take into account the purpose for which it was constructed. If the method was not developed to assess nutrient intake adequacy, its capacity to discriminate to what extent individuals' intakes are meeting their requirements will be an added value of the method. We have focused our search on the validity of the methods used for defining dietary patterns to assess micronutrient intake adequacy, i.e. the diet index under study or the dietary pattern defined as the healthiest one represents the most adequate in terms of nutrient intake. For this purpose, and to avoid correlation errors, only studies using two different methods to assess dietary data should be taken into account ${ }^{(38)}$. Few studies meeting this criterion were found, as most of them studied the association between dietary patterns and nutrient intake adequacy assessed with the same dietary data collection method.

From the results shown, diet indices are valid tools to evaluate intake adequacy for certain micronutrients. A revised DQI showed to be a valid tool for measuring the adequacy of intake of carotene, vitamin $\mathrm{C}$, vitamin $\mathrm{B}_{6}, \mathrm{Ca}$, folic acid, Fe and $\mathrm{Mg}$ in an adult population ${ }^{(12)}$. Biomarkers of intake showed that the HEI was valid to assess the adequacy of $\alpha$-carotene, $\beta$-carotene, $\beta$-cryptoxanthin, vitamin $\mathrm{C}$ and $\mathrm{Ca}^{(14,15)}$.

The correlation studies showed that the DDS had fair to moderate correlation coefficients for assessing adequacy for vitamin $\mathrm{A}$, vitamin $\mathrm{C}$, riboflavin, $\mathrm{Ca}, \mathrm{Zn}, \mathrm{K}$ and $\mathrm{P}$, but only among children and adult women ${ }^{(18,20)}$. The FVS correlated with the adequacy of vitamin $A$, thiamin, riboflavin, niacin, vitamin $B_{6}$, $\mathrm{Ca}$, folic acid, $\mathrm{Zn}$ and $\mathrm{Fe}$ in two samples of children ${ }^{(19)}$. The HEI has been demonstrated to be a good measure of $\mathrm{Ca}$ intake adequacy (moderate for vitamin A) in an adult population ${ }^{(21)}$.

Referring to factor analysis, the studies evaluating nutrient intake adequacy associated with dietary patterns showed that among men, the prudent pattern was valid to assess the intake adequacy of $\alpha$-carotene, lycopene and lutein ${ }^{(25)}$. For women, this methodology was valid for assessing the adequacy of $\beta$-carotene, vitamin $C$, vitamin $B_{6}$ and folic acid ${ }^{(29)}$.

According to the results from this review, vitamin $B_{12}$ and vitamin $\mathrm{E}$ are the micronutrients with less probability of being adequately assessed in the application of dietary patterns, regardless of whether these are defined by a priori or a posteriori methods.

\section{Acknowledgements}

The studies reported herein have been carried out within the EURRECA Network of Excellence (www.eurreca.org), financially supported by the Commission of the European Communities, specific Research, Technology and Development (RTD) Programme Quality of Life and Management of Living Resources, within the Sixth Framework Programme, contract no. 036196. The present report does not necessarily reflect the Commission's views or its future policy in this area.

B. R.-V. screened the literature, undertook analysis and wrote the paper. L. R.-B. contributed to the literature search strategy, screened part of the literature and commented on 
drafts of the paper. J. N. commented on drafts of the paper. M. A. M.-G provided expert advice on data interpretation and the writing of the paper. T. M. A. W. commented on drafts of the paper. L.S.-M was supervisor of the study and revised the paper providing expert advice on data interpretation and discussion of the paper.

The authors have no conflict of interests to report.

\section{References}

1. Madden JP \& Yoder MD (1972) Program evaluation: food stamps and commodity distribution in rural areas of central Pennsylvania. PA Agric Exp Stn Bull 78, 1-119.

2. Kant A (1996) Indexes of overall diet quality: a review. $J$ Am Diet Assoc 96, 785-791.

3. Kant AK (2004) Dietary patterns and health outcomes. $J$ Am Diet Assoc 104, 615-635.

4. Waijers PM, Feskens EJ \& Ocké MC (2007) A critical review of predefined diet quality scores. Br J Nutr 97, 219-231.

5. Moeller SM, Reedy J, Millen AE, et al. (2007) Dietary patterns: challenges and opportunities in dietary patterns research an Experimental Biology workshop April 1, 2006. J Am Diet Assoc 107, 1233-1239.

6. Arvaniti F \& Panagiotakos DB (2008) Healthy indexes in public health practice and research: a review. Crit Rev Food Sci Nutr 48, 317-327.

7. Newby PK \& Tucker KL (2004) Empirically derived eating patterns using factor or cluster analysis: a review. Nutr Rev 62, 5, 177-203.

8. Hu FB (2002) Dietary pattern analysis: a new direction in nutritional epidemiology. Curr Opin Lipidol 13, 1, 3-9.

9. van Dam RM (2005) New approaches to the study of dietary patterns. Br J Nutr 93, 573-574.

10. Fu ML, Cheng L, Tu SH, et al. (2007) Association between unhealthful eating patterns and unfavorable overall school performance in children. J Am Diet Assoc 107, 1935-1943.

11. Bailey RL, Gutschall MD, Mitchell DC, et al. (2006) Comparative strategies for using cluster analysis to assess dietary patterns. J Am Diet Assoc 106, 1194-1200.

12. Newby PK, Hu FB, Rimm EB, et al. (2003) Reproducibility and validity of the Diet Quality Index Revised as assessed by use of a food-frequency questionnaire. Am J Clin Nutr 78, 941-949.

13. Torheim LE, Barikmo I, Parr CL, et al. (2003) Validation of food variety as an indicator of diet quality assessed with a food frequency questionnaire for Western Mali. Eur J Clin Nutr 57, 1283-1291.

14. Hann CS, Rock CL, King I, et al. (2001) Validation of the Healthy Eating Index with use of plasma biomarkers in a clinical sample of women. Am J Clin Nutr 74, 479-486.

15. Weinstein SJ, Vogt TM \& Gerrior SA (2004) Healthy Eating Index scores are associated with blood nutrient concentrations in the third National Health And Nutrition Examination Survey. J Am Diet Assoc 104, 576-584.

16. Gerber MJ, Scali JD, Michaud A, et al. (2000) Profiles of a healthful diet and its relationship to biomarkers in a population sample from Mediterranean southern France. J Am Diet Assoc 100, 1164-1171.

17. Kennedy GL, Pedro MR, Seghieri C, et al. (2007) Dietary diversity score is a useful indicator of micronutrient intake in nonbreast-feeding Filipino children. J Nutr 137, 472-477.

18. Mirmiran P, Azadbakht L \& Azizi F (2006) Dietary diversity within food groups: an indicator of specific nutrient adequacy in Tehranian women. $J$ Am Coll Nutr 25, 354-361.
19. Steyn NP, Nel JH, Nantel G, et al. (2006) Food variety and dietary diversity scores in children: are they good indicators of dietary adequacy? Public Health Nutr 9, 644-650.

20. Mirmiran P, Azadbakht L, Esmaillzadeh A, et al. (2004) Dietary diversity score in adolescents - a good indicator of the nutritional adequacy of diets: Tehran Lipid and Glucose Study. Asia Pac J Clin Nutr 13, 56-60.

21. Foote JA, Murphy SP, Wilkens LR, et al. (2004) Dietary variety increases the probability of nutrient adequacy among adults. $J$ Nutr 134, 1779-1785.

22. Serra-Majem L, Ribas L, García A, et al. (2003) Nutrient adequacy and Mediterranean Diet in Spanish school children and adolescents. Eur J Clin Nutr 57, Suppl. 1, S35-S39.

23. Dubois L, Girard M \& Bergeron N (2000) The choice of a diet quality indicator to evaluate the nutritional health of populations. Public Health Nutr 3, 357-365.

24. Hatløy A, Torheim LE \& Oshaug A (1998) Food variety - a good indicator of nutritional adequacy of the diet? A case study from an urban area in Mali, West Africa. Eur J Clin Nutr 52, 891-898.

25. Hu FB, Rimm E, Smith-Warner SA, et al. (1999) Reproducibility and validity of dietary patterns assessed with a foodfrequency questionnaire. Am J Clin Nutr 69, 243-249.

26. Khani BR, Ye W, Terry P, et al. (2004) Reproducibility and validity of major dietary patterns among Swedish women assessed with a food-frequency questionnaire. J Nutr 134, $1541-1545$

27. Beaudry M, Galibois I \& Chaumette P (1998) Dietary patterns of adults in Québec and their nutritional adequacy. Can $J$ Public Health 89, 347-351.

28. Beaudry M, Galibois I \& Chaumette P (1996) Assessing the quality of food intake with the 1990 nutrition recommendations: four indicators proposed. J Can Diet Assoc 57, 7-11.

29. Newby PK, Weismayer C, Akesson A, et al. (2006) Long-term stability of food patterns identified by use of factor analysis among Swedish women. J Nutr 136, 626-633.

30. Borland SE, Robinson SM, Crozier SR, et al. (2008) Stability of dietary patterns in young women over a 2-year period. Eur $J$ Clin Nutr 62, 119-126.

31. Millen BE, Quatromoni PA, Copenhafer DL, et al. (2001) Validation of a dietary pattern approach for evaluating nutritional risk: The Framingham Nutrition Studies. J Am Diet Assoc 101, 187-194.

32. Quatromoni PA, Copenhafer DL, Demissie S, et al. (2002) The internal validity of a dietary pattern analysis. The Framingham Nutrition Studies. J Epidemiol Community Health 56, $381-388$.

33. Ruel MT (2003) Operationalizing dietary diversity: a review of measurement issues and research priorities. $J$ Nutr 133, 3911S-3926S.

34. Martínez ME, Marshall JR \& Sechrest L (1998) Invited Commentary: factor analysis and the search for objectivity. Am J Epidemiol 148, 17-19.

35. Schulze MB, Hoffmann K, Kroke A, et al. (2003) An approach to construct simplified measures of dietary patterns from exploratory factor analysis. Br J Nutr 89, 409-419.

36. Hoffman K, Schulze MB, Boeing H, et al. (2002) Dietary patterns: report of an international workshop. Public Health Nutr 5, 89-90.

37. van Dam RM (2005) New approaches to the study of dietary patterns. Br J Nutr 93, 573-574.

38. Willett W (editors) (2003) Nutritional Epidemiology. London: Oxford University Press. 